\title{
TIF 2.0: The Thal e-Course and TIF expert patients' programme for disease-related education and self-management skills in thalassaemia
}

\author{
Victoria Antoniadou, Michael Angastiniotis, Androulla Eleftheriou \\ Thalassaemia International Federation
}

\begin{abstract}
In response to the fundamental shift that has been taking place in the way chronic diseases are perceived and managed and the increasingly established role of patients as equal partners in the management of their condition, the Thalassaemia International Federation (TIF) has undertaken the design and development of a comprehensive online Expert Patients' Programme (EPP) for patients with thalassaemia. Focusing particularly on $\beta$-thalassaemia, the most severe form of thalassaemia, the goal of the programme is to develop patients' disease-related knowledge and self-care skills and enable them to co-manage their disease in a meaningful partnership with their treating physicians. An important goal of this ecourse is to empower patients to advocate for the improvement of national treatment services in every affected country.

The aim of this article is threefold:

(1) Relate TIF's EPP with the goals and outcomes of other EPPs, as they are made available in the literature.

(2) Describe the rationale and distinguishing features of TIF's EPP on the basis of learning theories of knowledge acquisition and attrition, and best practices from the scientific disciplines of Human Computer Interaction (HCI) and Technology-Assisted Learning (TEL).

(3) Relay the objectives of TIF's EPP and the intended international impact in relation to TIF's mission.
\end{abstract}

\section{Introduction}

“...little has been done to prepare patients for long-term management of their diseases [...] to accommodate their symptoms and functional limitations and deal with the emotional consequences. For their care to be effective, they must become adept at interpreting and reporting symptoms, judging the trends and tempo of their illness and participating with health professionals in management decisions." (Lorig et al. 1999, p. 5).

Self-management is understood as "the individual's ability to manage the symptoms, treatment, physical and psychosocial consequences and life style changes inherent to living with a chronic

Correspondence: Victoria Antoniadou, Thalassaemia International Federation.

E-mail: thalassaemia-va@thalassaemia.org.cy,

thalassaemia@cytanet.com.cy

This work is licensed under a Creative Commons Attribution 4.0 License (by-nc 4.0).

(C) Copyright V. Antoniadou et al., 2018

Licensee PAGEPress, Italy

Thalassemia Reports 2018; 8:7495

doi:10.4081/thal.2018.7495 condition" and should necessarily include the "ability to monitor one's condition and to effect the cognitive, behavioural and emotional responses necessary to maintain a satisfactory quality of life" (Barlow et al., 2002). Expert Patients' Programmes (EPPs) have been conceived as a tool for the management of chronic diseases, developing patients' self-care skills, self-efficacy and confidence and support them to achieve a better quality of life (Donaldson, 2003; Griffiths et al., 2007).

Professor Kate Lorig and her colleagues at Stanford University, California were the first to tap on the value of such programmes, developing and evaluating programmes for people with arthritis. The EPP tradition was soon adopted by several countries of the world e.g., in the United Kingdom, and countries in Europe (especially Scandinavia), Australasia, and North America for the needs of patients with various chronic diseases such as diabetes and in various formats i.e., lay-led by trained leaders and not health professionals such as nurses (Griffiths et at., 2005). With this approach, earlier EPPs in England aspired to reduce costs for national healthcare systems by reducing patients' hospital visits based on the rationale that increasing self-efficacy (confidence) is a prerequisite for behaviour change, which through improved self-management, may influence health and healthcare use (Griffiths et al., 2007).

The advent of Web 2.0 technology ushers in a new period for the health industry and EPPs, enhancing the possibilities and opportunities beyond time and physical space, fostering great potential for social support and thus new methods for enhancing self-management skills, self-esteem, and self-efficacy. Murray (2012) locates Web-based interventions in three main clinical areas: (1) self-management of long-term conditions (e.g., diabetes, heart disease, arthritis, and asthma), (2) health promotion (e.g., smoking cessation, alcohol reduction, sexual health, diet, and exercise), and (3) mental health (e.g., depression and anxiety). Practically, Medicine 2.0 has been applied in asynchronous and synchronous communication technologies, known as Virtual Healthcare Teams and Disease-Specific Patient Communities, which have achieved high levels of participation.

Unlike other types of technologies that usually cause stress to "digital immigrants" (Prensky, 2001), and require training and time before they are satisfactorily integrated into everyday practice, Web 2.0 are already part of people's everyday life and attract people of all ages. Web 2.0 tools have been used for: (1) social networking, (2) participation, (3) apomediation (guiding patients to relevant and accurate information, without troubling the specialist), (4) openness, and (5) collaboration, within and between healthcare consumers, caregivers, patients, health professionals, and biomedical researchers (Eysenbach, 2008; Boudry, 2015; Brulet, Llorca, \& Letrilliart, 2015).

The Thal e-Course is the first online component of TIF's EPP, exclusively created to fit the needs of thalassaemia patients, combining opportunities for both the acquisition of disease-related knowledge (e.g. thalassaemia history, facts, past and current advances in treatment and attempts to finding the final cure to prepare patients for long-term management of their diseases) and 
patient collaboration. This latter taps on the potential of social (community) support, a demonstrated valuable resource in supporting routine healthcare, encouraging patient self-efficacy in managing the disease and advocating for improvement of services.

\section{Thalassaemia patients as a sub-group of chronic patients with particular needs for knowledge and self-management skills}

Thalassaemia is an inherited condition in which the genes that are responsible for producing haemoglobin are damaged or absent. Haemoglobin is the protein inside the red blood cells that transports oxygen to the body organs and tissues. Damaged or insufficient haemoglobin causes severe anaemia (=lack of oxygen in the body) and inability to sustain human life. Thalassaemia treatment requires regular blood transfusions and iron chelation therapy, without which the patients are at increased risk of premature death preceded by poor quality of life. Decades of scientific research and clinical advances have transformed thalassaemia from a fatal disease of childhood to a chronic, well-managed disease. Patients' knowledge and self-management skills play a central role to such positive outcome. Evidence shows that well treated thalassaemia patients can lead a long and productive life, integrate and contribute to society.

Nevertheless, patient adherence to treatment is reported as one of the biggest challenges and risks for thalassaemia patients' survival and quality of life. The lifesaving therapeutic regime for thalassaemia patients imposes a challenging daily routine and imposes changes to patients' lives, especially during adolescence, changes that are not always easy to accept and/or comply with. Reports say that individuals may not comply with prescribed treatment regimens due to lack of full understanding of their importance and benefits over the adverse effects associated with nonadherence. Other factors that could reduce adherence could be fear caused by incomplete information on drug side effects, patient dislike for the medications and/or the rules around using them etc. (Odame \& Kirby-Allen, 2015). Experts agree that adherence to treatment can only be achieved through a deep understanding of what the condition involves, the holistic care it requires, as well as special nationally endorsed rights for thalassaemia patients.

Thalassaemia is no longer geographically confined; immigration flows have lead a growing prevalence of the disease worldwide, calling for awareness and education on the multifarious aspects and challenges of thalassaemia treatment. As research towards the final cure for thalassaemia continues, it is widely acknowledged, - and TIF's mission - that quality of treatment services should be ensured in every affected country. Awareness and regulated treatment is especially needed in poor-resourced countries which are at severe disadvantage, lacking even basic types of treatment and facing serious challenges in blood and drug safety and availability, precisely due to the absence of regulated policies for the safe and effective treatment in line with internationally-recognised patient rights for quality treatment. Thus, educating thalassaemia patients to pass on the knowledge and to advocate for better quality services and promote advocacy is a key tool in this mission and, as such, it lies at the core of TIF's EPP.

Given the above, patients with thalassaemia constitute a particular sub-group of patients who need to be able make meaningful day to day decisions such as taking medication, making lifestyle changes, or undertaking preventive action. They need to be able to modify behaviour to minimise undesirable outcomes, adjusting their social and work lives to accommodate their symptoms and functional limitations and deal with the emotional consequences. In this light, TIF's EPP targets positive outcome on two axes: (1) individual patient benefit and (2) patient community benefit (through greater involvement in patient associations to conduct advocacy work to promote national policies, quality of treatment and ensure safe and quality treatment for patients.

\section{Conceptual framework}

Conceptually, EPPs draw on social and psychological theories (Bandura, 1977) and the hypothesis that, (patients') self-efficacy i.e., ability to effectively cope with and manage with treatment, leads to the initiation of a coping behaviour - a behavioural change to promote adherence to prescribed treatment and self-manage or seek help to resolve everyday disease-related problems as they arise. The assumption underlying the development of EPPs is that patients' self-efficacy can be developed through comprehensive and scientifically sound disease-related knowledge and training, which can increase patients' self-esteem and place them in control over their disease.

Increasing self-efficacy correlates with increasing confidence/ self-esteem and determines the amount of effort that the patient will place on the management of his/her disease in the short and longterm as they face obstacles and aversive experiences e.g., reactions to blood transfusions and iron chelation therapies. When the patients are in control over the disease and not vice versa, the patients' quality of life improves as patients are more likely to adopt a healthy and positive lifestyle, contributing to a prolonged and healthier lifestyle (Donaldson, 2003). Furthermore, knowledge about their disease generates ability to interpret and report symptoms, and participate in management decisions.

At the same time, it has been widely accepted that patients know best how their condition affects them, the way they feel, their lifestyle and their ability to accomplish important daily and other activities, and can therefore offer unique and valuable insights about disease management to health professionals, national and international policy-makers in the areas of disease control and treatment. Patients cannot be passive recipients of treatment but active participants in the interventions that affect their everyday life and their survival (Angastiniotis \& Eleftheriou, this volume). At the same time, patient input is essential in all aspects of care, service provision and research and only possible when patients are well informed on their condition and its management (ibid.) with clear, accessible, relevant, scientifically-sound and reliable health information. The goal of EPPs is to provide the necessary knowledge and tools for patients to develop confidence and skills to work in partnership with health professionals (Shaw \& Baker, 2004), make informed decisions about their health, participate in their treatment, understand their symptoms and seek medical advice.

\section{Expert Patients' Programmes: A global evaluation}

Several research studies have been conducted to evaluate the impact of EPPs offered around the world against their initial objectives and delivery formats. These studies conclude that due to the heterogeneity of self-management interventions/EPPs and the lack of theoretical background is a significant factor in this outcome (Newman, Steed \& Mulligan, 2004), there is not a forthright yes or no answer as to the EPPs success or failure to achieve their initial objectives (Kew, Carr \& Crossingham, 2017).

Certain studies have identified modest changes in patients' self-efficacy, particularly in the case of ethnic minorities, but unclear value of these changes for the patients themselves compared with a reduction in symptoms or a gain in health related quality of life (Griffiths et al., 2007). Although there is some evidence that EPPs brought improvements in health behaviours, selfefficacy and satisfaction with the health care system, there is only 
limited evidence that EPPs have reached their objective to reduce visits to healthcare facilities as it set out to achieve (Lorig et al., 1999; Lorig et al., 2008).

\section{TIF's Expert Patients' Programme}

The underlying admission of the programme is that patients who become experts are likely to be less severely incapacitated and develop skills to cope with the physical and emotional consequences of their disease by adhering to treatment, collaborating with their treating physicians to find the best possible solutions to their individual challenges and evaluating options.

Following key principles of e-Learning 2.0, the Thal e-Course provides a Personal Learning Environment in which patients can learn about thalassaemia and acquire strong knowledge and selfcare skills in terms of disease monitoring, monitoring timetables, social habits, importance of adherence to treatment, and psychological support, which lie at the basis for any success in treatment. Malamed (2016) defines PLEs as "self-directed and evolving environment of tools, services and resources organized by a person seeking a way to accomplish lifetime learning, to create, and to connect with others of similar interests".

To the best of our knowledge, the Thal e-Course (TIF's EPP) is the first educational programme that is offered exclusively to thalassaemia patients and parents using dedicated tools and approaches, such as universal design, universally relevant content, and translation, to achieve a global outreach. Such tools and approaches are framed in the premises of HCI and TEL and affordances of Web2.0 tools, and with the goal of making the course accessible to all.

\section{Objectives}

Patients who complete the Thal e-Course should be able to:

1. Acquire in-depth knowledge about their condition, prognosis, complications, treatment options, research and clinical trials, other care services, psychosocial support.

2. Improve adherence, self-esteem, self-confidence.

3. Understand important policy issues, such as patient safety and patients' rights.

4. Develop necessary skills and confidence to develop effective partnerships with doctors and other health professionals.

5. Develop necessary skills to cope and manage daily life better: problem solving, goal setting, decision-making, using resources effectively, managing pain, fatigue, anger, depression, etc.

In the long run, TIF's vision for this programme is to develop these patients into core groups of Expert Patients across countries to advocate for better quality treatment services for thalassaemia patients in all affected countries.

\section{Methodology}

The general objective of this educational initiative is to develop the knowledge of patients with thalassaemia in order to give them the skills, confidence and motivation to take meaningful decisions and play a key role as partners in healthcare decisionmaking that concerns their own health, but also in a wider context of national health-policy decision-making.

To do so, the design of the course applied a broad range of factors that have an impact on teaching and learning (Anderson \& Krathwohl, 2001). For instance, the differentiation between "knowing that" (factual and conceptual knowledge e.g., vocabulary definitions and knowledge about drug categories and classifications, organ complications) and "knowing how" (procedural knowledge i.e., methods about when to use this information e.g., disease monitoring, nutrition). Anderson and Krathwohl (2001) specify that combining these knowledge components provides for meaningful learning and successful problem-solving and enable learners to remember, understand, apply, analyse, evaluate and create (their own approach to the disease).

\section{Content development}

The content development for the Thal e-Course was the result of a collaborative effort, which involved veteran thalassaemia patients, medical educators, and educationalists/instructional designers. (Figure 1).

\section{Phase 1: Content writing}

A group of 6 Expert Patients was identified and invited to form the "International Core Expert Patient Group" or ICEPG. The ICEPG members were selected because of their long-term experience and knowledge of medical, psychosocial and advocacy issues and patients' needs in these areas, because of their active contribution to educational national and international activities and their excellent communication skills and commitment.

This ICEPG was given the mandate to draw from personal experience and engagement with the national and international thalassaemia patient community (patient associations) to collect topics of interest and importance for thalassaemia patients and draft a first set of patient-centred educational material. Content development process was also informed by existing TIF book publications. TIF medical staff, consultants and course directors contributed to transforming this content into written material, ensuring its credibility and scientific integrity (Figure 2).

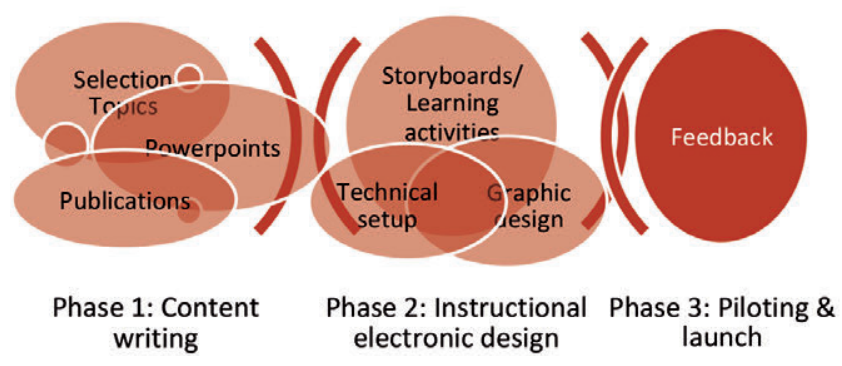

Figure 1. The development process of the Thal e-Course.

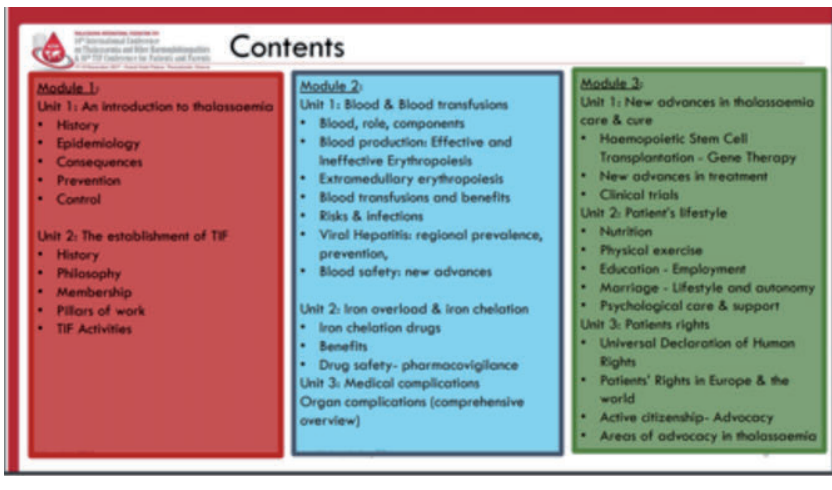

Figure 2. A summary of the contents of the Thal e-Course. 


\section{Phase 2: Instructional electronic design}

Instructional designers working on this project ensured that the material were patient-friendly and comprehensible, ensured, through the strategic use of Web 2.0 technologies, and valuable insights/findings from the field of HCI and TEL, that HCI consists of the three components (1) user, (2) computer, and (3) the interaction between (1) and (2) and the ways they can best work together. The goal in HCI is to bring the power of computers and communications systems to people in ways and forms that are both accessible and useful in our working, learning, communicating, and recreational lives (Foley, 1996).

$\mathrm{HCI}$, as a theoretical framework, integrates concepts and methods from computer science, design, and (ecological) psychology indicating that interfaces should be efficient and accessible to the users, and comprise opportunities for user action in order to contribute to his/her cognitive development (Figure 3).

HCI guiding principles (Norman, 1988), were combined with the Flemming and Mills' learning styles - The VARK ${ }^{1}$ modalities (1992) and Gardner's Multiple Intelligences ${ }^{2}$ (1996) - theories that account for best practices in pedagogy, and cater for affording opportunities for learning to patients (Table 1).

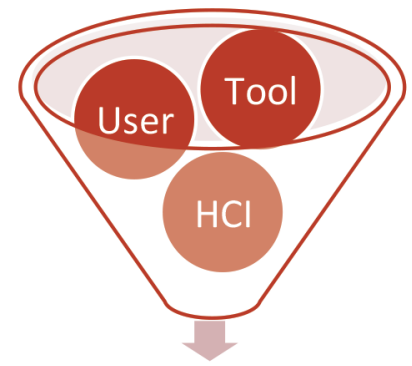

Thal e-Course

\section{Figure 3. Instructional design methodology}

Table 1. Activity and rationale breakdown for the Thal e-Course.

\begin{tabular}{|c|c|c|}
\hline Component & Profile & Actions taken \\
\hline User & 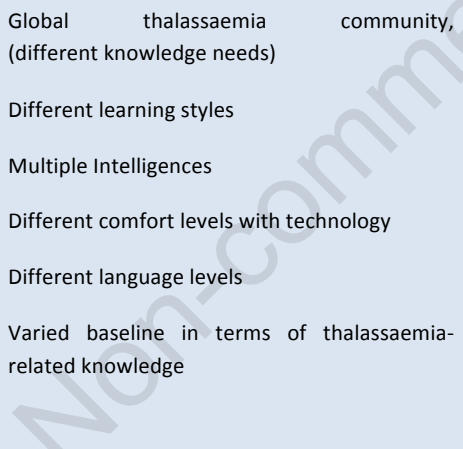 & $\begin{array}{l}\text { Adjusted factual knowledge re thalassaemia according to country } \\
\text { specifics } \\
\text { Primary and secondary information with summaries, relaunching and } \\
\text { quizzes } \\
\text { Content adjusted using assets e.g., videos, audios, timelines, graphics, } \\
\text { infographics, quizzes, forum (discussion board-DB)) } \\
\text { Translations to } 5 \text { key language of the targeted population e.g., English, } \\
\text { French, Arabic, Italian, Greek. } \\
\text { All level appropriate through topics covered and language used }\end{array}$ \\
\hline $\begin{array}{l}\text { Tool } \\
\text { (Moodle } \\
\text { platform, } \\
\text { course) }\end{array}$ & $\begin{array}{l}\text { Web-based: allows global outreach } \\
\text { Allows for record keeping } \\
\text { Allows for social interaction } \\
\text { Allows for tactile communication } \\
\text { Easy to use } \\
\text { Established learning system }\end{array}$ & $\begin{array}{l}\text { Statistics, constant monitoring of progress } \\
\text { Application for six principles of effective design (Norman, 1988) i.e., } \\
\text { visibility, feedback, affordance, mapping, constrains, consistency, } \\
\text { intuitive. } \\
\text { Engaging features e.g., popups, quizzes, DB etc.) }\end{array}$ \\
\hline $\begin{array}{l}\text { Interaction } \\
\text { user-tool }\end{array}$ & $\begin{array}{l}\text { Different comfort levels with technology } \\
\text { Different country specifics and needs } \\
\text { Social support- a key aspect in thalassaemia } \\
\text { management } \\
\text { Tool allows for tactile communication }\end{array}$ & $\begin{array}{l}\text { User-centred design: extensive attention to usability goals, user } \\
\text { characteristics, tasks and workflow are given at each stage of } \\
\text { the design process } \\
\text { Course content (lay language), forum, learning activities, } \\
\text { Quizzes: drop-down, drag and drop } \\
\text { DB: synchronous \& asynchronous interaction through a dedicated } \\
\text { forum }\end{array}$ \\
\hline
\end{tabular}




\section{Phase 3: Piloting \& launch}

Before final launch to the international patient community, the course was reviewed by TIF medical experts, the ICEPG (with varied technical knowledge and comfort level), and piloted by a small group of international patients in the context of a regional conference.

The target audience of this educational initiative consists of patients with thalassaemia in all 'affected' countries, and by extension their parents/families (at a later stage). The patients can attend this course in the comfort of their home and at their own time and pace, and are given the opportunity to discuss with experts on the various topics presented in the 3 modules that comprise the platform.

\section{Results}

Participant selection for the Thal e-Course consists of the following criteria: different language levels (CEFR: A1-C2), patient different baseline knowledge (motivation letter), participants from all affected countries, all patients with thalassaemia major.

\section{Evaluation strategies}

The impact of this course will be evaluated against its initial objectives using a mixed-method approach (quantitative and qualitative). Evaluation tools comprise progress statistics, pre and postquestionnaires on experience and impact on their knowledge, self efficacy scales evaluating also self-esteem, confidence in diseaserelated aspects of their life, and follow-up interviews at short (immediately after the course) and long-term. Other evaluation studies will also be pursued accordingly.

\section{Conclusions}

TIF's EPP is a Web-based intervention programme, especially designed for the particular needs of thalassaemia patients and seeks, amongst others to improve the knowledge, awareness, and understanding of patients regarding their disease via the provision of scientifically sound disease and health-related material uniquely delivered via interactive Web-based components (Barak et al., 2009: 4). Ensuring that patients comply with their treatment regimen, helps improve their health status and slows down the progression of disease/ complications. Knowledgeable patients can participate in patient communities and, very importantly, advocate for better healthcare services at the national and international level by offering unique insights based on experience at the national and international level.

At the same time, the changing doctor-patient relationship designates a patient who is more "involved" in their treatment (Shaw \& Baker, 2004); "resourceful" (Muir-Gray, 2002) or "autonomous" patients (Coulter, 2002). Empowering patients with knowledge and skills to provide those insights, that is enable them to have a say, take action shaping drug development processes and availability in every affected country for every affected patient, and influencing healthcare decision-making are central goals of many expert patients' programmes, currently in vigour, including TIF's Thal e-Course.

The Thal e-Course is the first web-based component of TIF's especially designed to fit the needs of the global patient community suffering from thalassaemia major with regard to disease-related knowledge, adherence to treatment, current advances, and patients' rights. As such, the uptake of the Thal e-Course by the global thalassaemia patient community is worthy of close monitoring and evaluation so as to trace its potential for marking an international impact in patient education and bring about positive outcomes in patient empowerment for effective policy-making on thalassaemia prevention and management in every affected country. It is also worthwhile to note whether the Course has the potential in fostering positive patient-reported outcomes in terms of adherence to treatment and quality of life.

\section{Acknowledgments}

Special thanks to veteran thalassaemia patients and International International Core Expert Patient Group, Mr Loris Angelo Brunetta, Mr George Constantinou, Mr Mahmood Hadipour Dehshal, Mr Riyad Elbard, Mr Mike Michael, Mr Loizos Pericleous, and Mr Anton Skafi for their unique insights into the needs of thalassaemia patients. We would like to also thank TIF medical consultants, Dr Farrukh Shah and Dr Perla Eleftheriou for their valuable insights while reviewing the content; and certainly TIF collaborators, Ms Martha Vasiliadou and Ms Helen Vrahimis for their expert input and true dedication to the technical implementation of this project.

\section{References}

Anderson LW, and Krathwohl DR, et al (Eds.) (2001) A Taxonomy for Learning, Teaching, and Assessing: A Revision of Bloom's Taxonomy of Educational Objectives. Allyn \& Bacon. Boston, MA (Pearson Education Group).

Angastiniotis \& Eleftheriou (2018). Patient Care: Unmet needs globally. this volume.

Bandura A (1977). Self-efficacy: Toward a unifying theory of behavioral change. PSYCHOLOGICAL REVIEW, 84(2), 191215. http://psycnet.apa.org/record/1977-25733-001 http://dx. doi.org/10.1037/0033-295X.84.2.191

Barak A, Klein B, and Proudfoot JG (2009). Defining internet-supported therapeutic interventions. Annual Behavioral Medicine 38(1):4-17.

Barlow J, Wright C, Sheasby J, Turner A, and Hainsworth J. Selfmanagement approaches for people with chronic conditions: a review. Patient Educ Couns. 2002; 48: 177-187.

Boudry C (2015). Web 2.0 Applications in Medicine: Trends and Topics in the Literature. Medicine $2.04(1): \mathrm{e} 2$.

Brulet A, Llorca G, Letrilliart L (2015). Medical wikis dedicated to clinical practice: a systematic review. In Journal of Medical Internet Research. 19: 17(2):e48. doi: /jmir.3574.

Coulter A. The autonomous patient-ending paternalism in medical care. London: Nuffield Trust, 2002.

Donaldson L (2003). Expert patients usher in a new era of opportunity for the NHS. BMJ : British Medical Journal, 326(7402), 1279-1280.

Dorer G. Developments in the expert patients programme. Presentation at the British Pharmaceutical Conference and Exhibition 2003, Harrogate International Centre, 15-17 September 2003.

Eysenbach G (2008). Medicine 2.0: Social Networking, Collaboration, Participation, Apomediation, and Openness. Journal of Medical Internet Research 10(3): e22. Available at: http://www.jmir.org/2008/3/e22/

Flemming and Mills (1992). Not Another Inventory, Rather a Catalyst for Reflection. From To Improve the Academy, Vol. 11, 137 Available at http://vark-learn.com/wp-content/uploads/ 2014/08/not_another_inventory.pdf

Foley JD (1996). Human-Computer Interaction Technologies in Japan. JTEC Panel Report. Available at http://www. wtec.org/loyola/hci/c1_s1.htm 
Gardner H (1996). Probing more deeply into the theory of multiple intelligences. Sage Journals. Available at http://journals. sagepub.com/doi/pdf/10.1177/019263659608058302

Griffiths C, Motlib J, Azad A, Ramsay J, Eldridge S, Feder G, Barlow J (2005). Randomised controlled trial of a lay-led self-management programme for Bangladeshi patients with chronic disease. The British Journal of General Practice, 55(520), 831-837.

Griffiths C, Foster G, Ramsay J, Eldridge S, Taylor S (2007). How effective are expert patient lay led) education programmes for chronic disease? BMJ. 2007 Jun 16; 334(7606): 1254-1256. Available at https://www.ncbi.nlm.nih.gov/pmc/articles/PMC 1892511/ doi: 10.1136/bmj.39227.698785.47

Kew KM, Carr R, Crossingham I (2017). Lay-led and peer support interventions for adolescents with asthma. Cochrane Database of Systematic Reviews 2017, Issue 4. Art. No.: CD012331. DOI: 10.1002/14651858.CD012331.pub2.

Lorig KR, Sobel DS, Stewart AL, Brown BW Jr, Bandura A, Ritter P, Gonzalez VM, Laurent DD, Holman HR (1999). Evidence suggesting that a chronic disease self-management program can improve health status while reducing hospitalization: a randomized trial. Med Care. 37(1):5-14. Available at https:// www.ncbi.nlm.nih.gov/pubmed/10413387

Lorig KR, Ritter PL, Dost A, Plant K, Laurent DD, Mcneil I (2008). The expert patients programme online, a 1-year study of an Internet-based self-management programme for people with long-term conditions. Sage Journals. Available at http://journals.sagepub.com/doi/abs/10.1177/1742395308098886
Malamed C (2016). Models For Designing Your Personal Learning Environment [blog]. Available at http://theelearningcoach.com/ elearning2-0/designing-personal-learning-environment/.

Muir Gray JA (2002). The resourceful patient. Oxford: eRosetta Press. Available at http://ebm.bmj.com/content/7/6/168

Murray E (2012). Web-Based Interventions for Behavior Change and Self-Management: Potential, Pitfalls, and Progress. Med 2 0 Journal of Medical Internet Research 1(2):e3. Available at: http://www.medicine20.com/2012/2/e3Norman, D. A. (1988). The Design of Everyday Things. New York: Doubleday. ISBN: 0-385-26774-6.

Newman S, Steed L, and Mulligan K (2004) Self-management interventions for chronic illness. The Lancet. Available at https://www.ncbi.nlm.nih.gov/pubmed/15500899/

Odame I and Kirby-Allen M (2015). Learning for Life Series: Adherence to Iron Chelators, Hydroxyurea and Other Therapies. Patients \& Families and Health Care Providers Townhall Forum (hosted on September 12, 2015). Available at http://www.thalassemia.ca/event-details/2166/

Prensky M (2001). Digital Natives, Digital Immigrants. In On the Horizon. MCB University Press 9(5).

Shaw J, \& Baker M (2004). "Expert patient"-dream or nightmare?: The concept of a well informed patient is welcome, but a new name is needed. BMJ: British Medical Journal, 328(7442), 723-724.

van Lier L (2002). The ecology and semiotics of language learning: A sociocultural perspective. Boston: Kluwer Academic. 